\title{
Empirical Study on Economies of Scale in China Manufacturing
}

\author{
WANG Lingyao ${ }^{1, \mathrm{a}}$, ZHOU Yaodong 2 ,b \\ ${ }^{1}$ School of Economics and Management, Beijing Jiaotong University, Beijing, China \\ ${ }^{2}$ School of Economics and Management, Beijing Jiaotong University, Beijing, China
}

\begin{abstract}
The paper is based on Chinese industrial enterprises database, applying the method of translog cost function to measure the economies of scale in manufacturing during the period between 2000 to 2013 . The result shows that the mean of scale economies (SCE) is between 0.993 and 0.996 , which indicates slight diseconomies of scale. From the perspective of the SCE variation trend, before 2010, there was a decreasing trend year by year, and the variation remained stable after 2010. Considering manufacturing heterogeneity, the paper divides manufacturing into nine groups to measure economies of scale. The group measurement results show that mining industry and light industry have high economies of scale, but in a decreasing state, other sub-sectors show slight diseconomies of scale and in a stable state.
\end{abstract}

\section{Introduction}

Economies of scale is the key indicator to measure the long-term cost of enterprises, and it is one of the important determinants of the long-term sustainable development of the manufacturing industry, especially the large-scale manufacturing enterprises with mature technological conditions. Since China's reform and opening up, the continuous development of manufacturing has become the key of boosting the economy. After entering the $21 \mathrm{st}$ century, with the gradual disappearance of the demographic dividend and the stricter of environmental constraints, the development of manufacturing is facing severe challenges. It is important to re-evaluate the economies of scale of the manufacturing industry. It is of great significance to determine the competitive position of various manufacturing sectors and promote the transformation and upgrading of the manufacturing industry.

\section{Literature Review}

Regarding the measurement of economies of scale in China's manufacturing industry and its sub-sectors, the existing literatures mostly used listed company data and industry data as samples for measurement. For example, Yuan Guiqiu and Zhang Lingdan (2010) take 276 listed companies in the manufacturing industry between 2000 and 2006 as a sample.[1] Zhu Yan (2013) analyzed 883 listed companies in the manufacturing industry during 2007-2011.[2] Anguo et al. (2011) selected data from 17 manufacturing segments for analysis.[3] Different scholars have disputed about the measurement of economies of scale in the manufacturing sub-sectors. Zhang Lingdan (2010) believed that there is a large heterogeneity among manufacturing sub-sectors during 2000-2006.[4] Zhu Yan (2013) believed that the difference in manufacturing sub-sectors is not large during 2007-2011.[2]

Regarding the measurement of economies of scale in foreign manufacturing and its sub-sectors, many scholars measured the optimal scale. The implicit assumption is that there is economies of scale when the enterprise's scale is lower than the optimal scale, and there is diseconomies of scale when the scale is higher than the optimal scale. For example, Lila J. Truett and Dale B. Truett (2007) measured the scale economy of the French automobile industry.[5] David S. Saal et al. (2011) measured the economies of scale in the water resources and wastewater treatment industries.[6] Orjan Mydland et al. (2019) analyzed Norwegian power industry.[7]

The marginal contribution of this paper is using Chinese industrial enterprises database, which is more representative, applying the method of translog cost function, which is more accurate, and analyzing its trend characteristics. Further, this paper divides manufacturing into nine groups to measure economies of scale and variation trends in the sub-sectors.

\section{Method, Variables and Data}

\subsection{Method}

The translog cost function was first proposed by Christensen and Greene in 1976, and it is suitable for enterprises with multiple inputs and multiple outputs to analyze the cost situation.[8] After logarithmic input and

àwanglingyao99@163.com; bydzhou@bjtu.edu.cn 
output data, the cost function is not restricted by constant elasticity of substitution of factor and constant elasticity of transformation.

To a firm who produces $m$ outputs $\left(y_{i}\right)$ and uses $n$ inputs $\left(p_{j}\right)$, the translog cost function can be written as:

$\ln T C=\alpha_{0}+\sum_{i=1}^{m} \alpha_{i} \ln y_{i}+\sum_{j=1}^{n} \beta_{j} \ln p_{j}+\frac{1}{2} \sum_{i=1}^{m} \sum_{k=1}^{m} \alpha_{i k} \ln y_{i} \ln y_{k}$ $+\frac{1}{2} \sum_{j=1}^{n} \sum_{k=1}^{n} \beta_{j t} \ln p_{j} \ln p_{t}+\sum_{i=1}^{m} \sum_{j=1}^{n} \gamma_{i j} \ln y_{i} \ln p_{j}+\varepsilon$

In this function, $T C$ represents the total cost of the manufacturing enterprise, and $y_{i}$ represents the amount of the $i$-th output, $i=1,2 \ldots m ; p_{j}$ represents the price of the $j$ th input, $j=1,2 \ldots n ; \varepsilon$ is error terms. $\alpha_{0}, \alpha_{i}, \beta_{j}, \alpha_{i k}, \beta_{j t}, \gamma_{i j}$ are the estimated parameters of the equation.

In order to meet the linear homogeneity of the function, the estimated parameters need to meet the following constraints:

$\sum_{j=1}^{n} \beta_{j}=1, \sum_{i=1}^{n} \beta_{j t}=0, \sum_{j=1}^{n} \gamma_{i j}=0, \alpha_{i k}=\alpha_{k i}, \beta_{j t}=\beta_{t j}$,
$\forall i, k=1,2 \ldots m j, t=1,2 \ldots n$ (2)

Calculating the cost elasticity from the translog cost function, and obtaining the scale economies coefficient (SCE), which is used to determine whether enterprises are in the economies of scale situation:

$S C E=T C / \sum_{i=1}^{m} Y_{i} M C_{i}=1 /\left(\sum_{i=1}^{m} \frac{\partial \ln T C}{\partial \ln y_{i}}\right)$

$=1 /\left(\sum_{i=1}^{m} \alpha_{i}+\sum_{i=1}^{m} \sum_{k=1}^{m} \alpha_{i k} \ln y_{i}+\sum_{i=1}^{m} \sum_{j=1}^{n} \gamma_{i j} \ln p_{j}\right)$

The SCE refers to the degree of cost change when output increases by $1 \%$. If $S C E>1$, it means that the company's output increases by $1 \%$, the cost change is less than $1 \%$, and the company achieves economies of scale. If $S C E<1$, it means the company is in the state of diseconomies of scale.

\subsection{Variables}

In this article, $m=1, n=3$, which means there are one output and three input prices. Using the main business cost to represent total cost, and using main business income to represent total revenue. The price of labor (pla) is the ratio of payable wages to the average number of employees. The price of fixed assets $(p f a)$ is the ratio of the current year's depreciation to the original value of the fixed assets. The price of material (pma) is the ratio of direct materials to industrial intermediate inputs.

\subsection{Data}

In this article, $m=1, n=3$, which means there are one output and three input prices. Using the main business cost to represent total cost, and using main business income to represent total revenue. The price of labor (pla) is the ratio of payable wages to the average number of employees. The price of fixed assets $(p f a)$ is the ratio of the current year's depreciation to the original value of the fixed assets. The price of material (pma) is the ratio of direct materials to industrial intermediate inputs.

The data is selected from the Chinese industrial enterprises database between 2000 to 2013. Using Access to process the data as follows: (1) Removing companies that entered the market after 2000 and exited the market before 2013. (2) Deleting enterprises with key financial data, such as main business income, total assets, and net assets, is negative. (3) Deleting the enterprises whose material prices less than 0. (4) Using Stata to supplement missing data of industrial intermediate inputs after 2008. (5) Based on the year 2000, adopting PPI index to deflate the data of main business cost, wages payable, intermediate input and direct materials, and adopting CPI index to deflate the main business income data, eliminating the impact of price changes. After data processed, there are 18,175 manufacturing companies.

TABLE I. DESCRIPTIVE StATISTICS ON THE SAMPLE

\begin{tabular}{|c|l|l|l|l|l|}
\hline Variables & $\boldsymbol{n}$ & Mean & $\begin{array}{l}\text { Std } \\
\text { Error }\end{array}$ & Min & Max \\
\hline lnincome & 247876 & 11.303 & 1.397 & 1.603 & 19.669 \\
lnmaincost & 247876 & 11.108 & 1.414 & 0.706 & 19.516 \\
lnpla & 247876 & 2.776 & 0.799 & -5.617 & 14.058 \\
lnpfa & 247876 & -2.892 & 0.738 & - & 8.443 \\
lnpma & 247876 & -0.235 & 0.372 & - & 0.430 \\
\hline
\end{tabular}

\section{Empirical Results}

\subsection{Empirical results of entire manufacturing}

To avoid spurious regression, using EViews10 to apply unit root test for each variable before regression. Because missing data has been removed from empirical data, there are unbalanced panel. Therefore, the methods of IPS, Fisher-ADF and Fisher-PP are used. Unit root test results show that all the selected variables are stationary series.

The table 2 presents the regression results with fixed effects and random effects.

TABLE II. PARAMETER ESTIMATION RESULTS OF TRANSLOG COST FUNCTION

\begin{tabular}{|l|l|l|}
\hline \multirow{2}{*}{ parameter } & \multicolumn{2}{|l|}{ lnmaincost } \\
\cline { 2 - 3 } & fixed effects & $\begin{array}{l}\text { random } \\
\text { effects }\end{array}$ \\
\hline \multirow{3}{*}{$\alpha_{0}$} & $\begin{array}{l}-0.0650057 \\
* * *\end{array}$ & - \\
\cline { 2 - 3 } & $(0.004)$ & $(0.000)$ \\
\hline \multirow{2}{*}{$\alpha_{1}$} & $0.9787503 * * *$ & $0.9905568 * * *$ \\
\cline { 2 - 3 } & $(0.000)$ & $(0.000)$ \\
\hline \multirow{2}{*}{$\beta_{1}$} & - & - \\
\hline
\end{tabular}




\begin{tabular}{|c|c|c|}
\hline & $(0.000)$ & $(0.000)$ \\
\hline \multirow{2}{*}{$\beta_{2}$} & -0.0021084 & -0.0039562 \\
\hline & $(0.539)$ & $(0.250)$ \\
\hline \multirow{2}{*}{$\beta_{3}$} & $0.1722063 * * *$ & $0.1537863 * * *$ \\
\hline & $(0.000)$ & $(0.000)$ \\
\hline \multirow[b]{2}{*}{$\alpha_{11}$} & $0.000685^{* * *}$ & -0.000283 \\
\hline & $(0.048)$ & $(0.371)$ \\
\hline \multirow{2}{*}{$\beta_{12}$} & $0.018991 * * *$ & $0.0185674 * * *$ \\
\hline & $(0.000)$ & $(0.000)$ \\
\hline \multirow{3}{*}{$\beta_{13}$} & - & - \\
\hline & $0.0231158 * * *$ & $0.0200494 * * *$ \\
\hline & $(0.000)$ & $(0.000)$ \\
\hline \multirow{2}{*}{$\beta_{23}$} & $0.0079852 * * *$ & $0.0112798 * * *$ \\
\hline & $(0.000)$ & $(0.000)$ \\
\hline \multirow{2}{*}{$\beta_{11}$} & $0.0016466 * * *$ & $0.0017154 * * *$ \\
\hline & $(0.000)$ & $(0.000)$ \\
\hline \multirow{2}{*}{$\beta_{22}$} & $\begin{array}{l}\overline{-} \\
0.0057964 * * *\end{array}$ & $\begin{array}{l}- \\
0.0056332 * * *\end{array}$ \\
\hline & $(0.000)$ & $(0.000)$ \\
\hline \multirow{2}{*}{$\beta_{33}$} & $0.034741 * * *$ & $0.0464892 * * *$ \\
\hline & $(0.000)$ & $(0.000)$ \\
\hline \multirow[b]{2}{*}{$\gamma_{11}$} & $0.0027867 * * *$ & $0.002563 * * *$ \\
\hline & $(0.000)$ & $(0.000)$ \\
\hline \multirow{2}{*}{$\gamma_{12}$} & $\begin{array}{l}- \\
0.0041063 * * *\end{array}$ & $\begin{array}{l}- \\
0.0037678 * * *\end{array}$ \\
\hline & $(0.000)$ & $(0.000)$ \\
\hline \multirow[b]{2}{*}{$\gamma_{13}$} & $0.0022136 * * *$ & $0.0079868 * * *$ \\
\hline & $(0.003)$ & $(0.000)$ \\
\hline
\end{tabular}

Notes: p-value in parentheses, $* * *$ and $* * *$ indicate significance at $0.1,0.05$ and 0.01 levels respectively.

The empirical results of fixed effects and random effects show that the coefficients both are significant at the level of $1 \%$. Hausman test results show that $p=0.000$, reject the null hypothesis, the function should establish with fixed effects. Using the estimated parameters, calculating the coefficient of scale economy (SCE) from 2000 to 2013.

$$
S C E=1 /\left(\sum_{i=1}^{m} \frac{\partial \ln T C}{\partial \ln y_{i}}\right)
$$

$=1 /\left(\alpha_{1}+\alpha_{11} \ln\right.$ income $\left.+\gamma_{11} \ln p l a+\gamma_{12} \ln p f a+\gamma_{13} \ln p m a\right)$ $=1 /\left(\begin{array}{c}0.9787503+0.000685 * \ln \text { income }+0.0027867 * \ln p l a \\ -0.0041063 * \ln p f a+0.0022136 * \ln p m a\end{array}\right)$

The results show that there were average 884 companies $S C E>1$ per year, who were in the state of economies of scale. And average 16,621 companies $S C E<1$ each year, who were in the state of diseconomies of scale. The proportion of enterprises that achieved economies of scale is $4.99 \%$, most manufacturing companies were in the state of diseconomies of scale. Figure 1 shows the trend of average SCE per year of entire manufacturing industry.

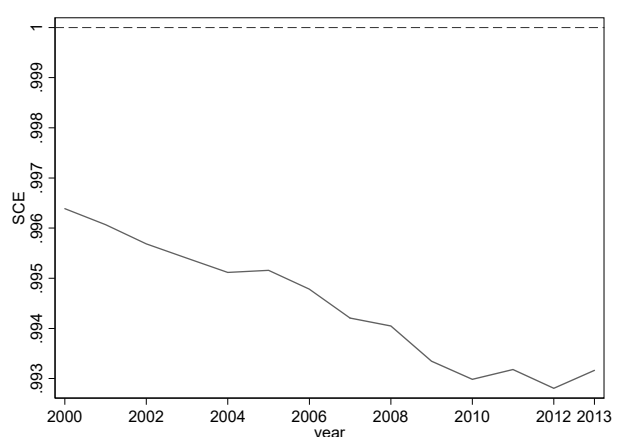

Figure 1. The Average SCE of Entire Manufacturing Industry

It can be seen from the mean curve that during 20002013 , the coefficient of scale economy had a maximum value of 0.996 and a minimum value of 0.993 , showing a slight diseconomies of scale. From the perspective of the trend, the annual average SCE is divided into two stages in 2010, before 2010, showing a downward trend, and after 2010 , it gradually stabilized. The turning point in 2010 may due to the outbreak of the financial crisis in 2009, which had a severe negative impact to the manufacturing industry. Subsequently, Chinese government implemented a series of policies to stimulate the economy that promote the transformation and upgrading of the manufacturing industry.

\subsection{Empirical results of manufacturing sub- sectors}

Considering that the manufacturing includes 41 industries and there is heterogeneity among sub-sectors. It's necessary to discuss economies of scale in manufacturing sub-sectors. Because the differences in manufacturing processes and product diversity, dividing 18,175 companies into 9 groups based on industry codes. Since the definition of "other manufacturing industries", whose industry code is 41 , is not clear, it cannot be classified and would not be discussed. As the industry codes of Chinese industry enterprises database have changed many times during 2000-2013, this article is based on the code in 2013. The detailed grouping is shown in the following table.

TABLE III. THE GROUPS OF MANUFACTURING

\begin{tabular}{|c|l|c|c|}
\hline Group & $\begin{array}{l}\text { Industry } \\
\text { codes }\end{array}$ & $\begin{array}{l}\text { Number } \\
\text { of } \\
\text { companies }\end{array}$ & Detailed industries \\
\hline 1 & $06-12$ & 414 & $\begin{array}{c}\text { Mineral mining } \\
\text { industry }\end{array}$ \\
\hline 2 & $13-16$ & 1667 & $\begin{array}{c}\text { Food manufacturing } \\
\text { industry }\end{array}$ \\
\hline 3 & $17-24$ & 3823 & Light industry \\
\hline 4 & $26-29$ & 2982 & $\begin{array}{c}\text { Chemical industry; } \\
\text { Pharmaceutical industry }\end{array}$ \\
\hline 5 & $25,30-$ & 2628 & $\begin{array}{c}\text { Petroleum refining } \\
\text { industry; primary metal } \\
\text { industry }\end{array}$ \\
\hline
\end{tabular}




\begin{tabular}{|c|c|c|c|}
\hline 6 & $34-$ & 2878 & $\begin{array}{c}\text { Large machinery } \\
\text { manufacturing industry }\end{array}$ \\
\hline 7 & $38-43$ & 2275 & $\begin{array}{c}\text { Electrical equipment } \\
\text { manufacturing industry }\end{array}$ \\
\hline 8 & 42 & 13 & $\begin{array}{c}\text { Comprehensive } \\
\text { Utilization of Waste } \\
\text { Resources }\end{array}$ \\
\hline 9 & $44-46$ & 1406 & Utility industry \\
\hline
\end{tabular}

Due to there are only 13 companies in the group 8 survived from 2000 to 2013, which is a small sample and will affect the stability of the regression. Therefore, we do not measure and discuss the economies of scale of the industry.

Testing the other 8 groups using fixed effects and random effects model. After Hausman's test, $p=0.000$, fixed effect regression should be used. Based on the results of parameter estimation, measuring the coefficient of scale economy (SCE), and calculating the annual average SCE. The results show that $82.49 \%$ of the enterprises in the mining industry, $54.99 \%$ of the enterprises in light industry, and $20.46 \%$ of the enterprises in the intermediate products industry had realized economies of scale. In the rest groups, only a few companies were in the state of scale economy, and most of them were in the state of diseconomy of scale.

Further, describing the average SCE variance trend over time. Results show that there were significant heterogeneity across sub-sectors. In the period of 20002013, the mining industry had been in the economies of scale. In addition, the average SCE of the light industry was very close to 1 , which basically achieved economies of scale. Other industries' average SCE had always been less than 1, and generally around 0.99 , with slight diseconomies of scale.

Most manufacturing companies in the state of diseconomies of scale. However, in these industries, corporate competitiveness and technological advantages still exist. The existence of economies of scale is related to many factors, such as the macroeconomic cycle, the life cycle of the industry, the degree of market competition, the stage of enterprise development, technical conditions, and internal management.

\section{Conclusions}

The thesis adopts the method of translog cost function, using the panel data of Chinese industrial enterprises database from 2000 to 2013, measuring the economies of scale of the Chinese entire manufacturing industry and its sub-sectors. The conclusions are as follows: (1) Most manufacturing companies are in diseconomies of scale. For every $1 \%$ increase in output, the average cost increases by more than $1 \%$. However, the average SCE of the entire manufacturing industry is between 0.993 and 9.986, that means the degree of diseconomies of scale is slight. Regarding the changing trend of the economies of scale of the overall manufacturing industry, it showed a decreasing trend before 2010, and a stable trend after 2010. (2) Large heterogeneity among manufacturing sub-sectors. The mining industry and light industry were in the state of economies of scale. The food processing industry, chemical and medical industry, processing industry, transportation equipment industry, electrical and communication equipment industry, and public utility industry were in the state of slight diseconomies of scale. After measuring the variance of the average SCE in various industries, it was found that the economies of scale of mineral mining industry, chemical industry and medical industry showed decline in different degrees. The economies of scale in other industries have not changed significantly.

\section{Acknowledgment}

The National Social Science Fund of China, "Research on Water Management System and Operation Mechanism of Chinese Cities and Towns Under New Urbanization" (15BJY054).

\section{References}

1. YUAN Guiqiu, ZHANG Lingdan. An Anlysis of factors influencing Scale Economy of the Manufacturing in China [J]. The Journal of Quantitative \& Technical Economics, 2010(3):42-54.

2. ZHU Yan. Study on the Relationship between Economies of Scale and Asset Structure of Listed Manufacturing Companies [D]. Dalian: Dalian University of Technology, 2013.

3. Anguo L., Ge G., Kaizhong Y. Returns to scale in the production of selection manufacturing sectors in China [J]. Energy Procedia, 2011,5:604-612.

4. ZHANG Lingdan, An Anlysis of factors influencing Scale Economy of the Manufacturing in China [D]. Hangzhou: Zhejiang Gongshang University, 2010.

5. Lila J.Truett, Dale B.Truett. A cost-based analysis of scale economies in the French auto industry[J]. International Review of Economics and Finance, 2007, 16:369-382.

6. David S Saal, Pablo Arocena, Alexandros Maziotis, Thomas Triebs. Scale and scope economies and the efficient configuration of the water industry[D]. Birmingham: Aston University, 2011.

7. Ørjan Mydland, Subal C. Kumbhakar, Gudbrand Lien, Roar Amundsveen, Hilde Marit Kvile. Economies of scope and scale in the Norwegian electricity industry[J]. Economic Modelling,2019, $9(8)$.

8. Laurits R. Christensen and William H, Greene.: Economies of Scale in U.S. Electric Power Generation[J]. Journal of Political Economy,1976,84(4):655-676 